MedieKultur | Journal of media and communication research | ISSN 1901-9726

Editorial

\title{
Intimacy and visual communication in social media
}

\section{Anne Mette Thorhauge, Jakob Johan Demant and Stinne Gunder Strøm Krogager}

\author{
MedieKultur 2020, 67, 1-5
}

Published by SMID | Society of Media researchers In Denmark | www.smid.dk The online version of this text can be found open access at www.mediekultur.dk

Sharing (intimate) photos has become an integral part of close relationships in the age of social media. Most young people use social media as a way to establish and maintain strong social ties rather than as a way of connecting to public life. This pattern of use includes the sharing of photos and videos with intimate and sexual content, such as nudes, intimate situations, and other types of self-disclosure. Given that the primary public and academic interest has been related to situations where the process has gone wrong and people have been hurt, these photos and videos are often associated with risk, worries, and moral disdain. However, these cases are part of a broader range of social practices, which are for the most part unproblematic and mundane. The sharing of intimate photos should be acknowledged as part of a more general act of (mutual) self-disclosure to establish trust as well as an non-patalogical exploration of sexuality and social identities. In both cases, the sharing of intimate photos becomes part of more general processes of intimacy and close relationships that we should be careful not to reject or problematize as a whole. Accordingly, in this themed issue we would like to move beyond the stories of problem youth and move instead towards a more empirically grounded and systematic analysis of the complex ways in which the sharing of intimate photos becomes part of everyday life practices, including friendship, courtship, trust, and intimacy.

A recent study based on Youthprofile data (Ungeprofilundersøgelsen) has shown that around 14 pct. of Danes aged 12-25 receive nude images that they know to be shared without consent (Harder et al., 2019). It further showed that 80 pct. of the receivers of 
images did not forward them, and thus we may think of the majority of receivers as intervening in image-based sexual abuse by not forwarding received images. Therefore, resharing is not an automatic reaction among receivers. In general, the one characteristic that the offenders, sexters, and receivers in the aforementioned study have in common is that on average they have poorer self-control compared to the other respondents (i.e. have personality characteristics enabling a person to defer short-term goals and sensations). Furthermore, it is shown that self-control has a moderate effect on image-based sexual abuse. Poor self-control further heightens the probability of offending, independent of the effects of gender and age. As such, this study indicates that the processes for understanding both benign and problematic picture sharing is a complicated interaction between psychological, cultural and social processes.

In contrast to this quantitative study, the articles in this themed issue are based on qualitative explorations that focus on the diverse social contexts of intimate photo-sharing. This includes the contexts where photos are produced and shared, the digital media that enable these activities, and the far-reaching consequences that this has for particular individuals. These articles offer valuable insights into everyday contexts of intimate photo-sharing and they contribute rich qualitative accounts of phenomena that are only indirectly addressed in the previous survey.

These articles describe the broad range of social purposes intimate photo-sharing serves in individual contexts of communication. While general terms such as sexting, revenge porn or nudes may give the impression of somewhat unified activities or practices, the qualitative studies in this themed issue tell us something else. Intimate photos may be taken and shared as part of a wide range of purposes, such as playing with sexuality and pornographic expressions (Harder et al.), establishing intimate relationships with friends (Bonitz \& Thorhauge), or negotiating positions among peers (Mandau). Similarly, digital sexual assault may take many different forms and cannot be reduced to the angry ex-boyfriend story (Mortensen). While a photo may look like porn, it is, ultimately, the content, contexts, and consent that it involves which define it as an instance of communication (Harder et al.).

The articles in this issue of MedieKultur contribute to the necessary illumination of the complex interplay between the original contexts of communication and the wider techno-social systems within which the texts circulate and proliferate. What may have been communicated consensually with one partner or purpose in mind, can take on a wide range of unpredictable directions and may be attributed with a range of additional interpretations that were not part of the original communication context. Rasmussen and Søndergaard emphasize the overwhelming potentiality that digital photos possess thanks to the affordances of digital media systems. This creates highly complex social and technological environments, which young people have to navigate. Uldbjerg similarly addresses how this technologically mediated context collapse increases the complexity 
and extension of sexual assault by including the notion of potential onlookers and potential harassment as part of the trauma that victim-survivors will have to deal with.

Finally, a persistent theme across the differences of the articles in this themed issue is the pronounced gender differentiation and sexual double standards that pervade the phenomenon of intimate photo-sharing. Research asserts that gendered double standards, digital anonymity, and physical separation make it especially difficult to effectively deter young people from engaging in these new forms of abuse (Henson et al., 2019; Walrave et al., 2018). However, more recent studies have also provided reasons to believe that a new ethics for digital behaviour is developing among young people, who are developing skills to distinguish between what is appropriate and abusive behaviour when it comes to image sharing (Albury \& Crawford, 2012; Ravn \& Roberts, 2019). The articles in this issue help us to explain some of the social dynamics that bring about such double standards, and where they are changing. This includes the negotiation of gender and social positioning among groups of peers (Mandau), the range of strategies available to young men and young women, respectively, when dealing with intimate photo-sharing and handling risk (Rasmussen \& Søndergaard; Uldbjerg), and the way in which many of the young women in these studies are simultaneously potential victims, and active participants in the slutshaming and victim-blaming related to intimate photo-sharing (Hansen, Bonitz \& Thorhauge). In all cases, it is clear that the sexual double standards can be ascribed to more general gender norms and practices in the social world, and is not merely a property of intimate photo-sharing.

In their totality, the different contributions to this themed issue offer rich, qualitative insights into the social purposes, critical reflections, individual strategies, and experiences of intimate photo-sharing across a range of contexts.

In "Tailored pornography': content, context and consent in young women's sexting" Sidsel Harder, Julie Johanne Vittet Bentzen, Jakob Demant and Claire Maxwell examine the active engagement of a group of women with pornography and how they relate this to their practices of intimate photo sharing. The women in this study actively use porn, yet differentiate their intimate photos from pornography at the level of content, context, and consent.

In "Friends, lovers, risk and intimacy: Risk-taking as a socially meaningful practice" Mareike Bonitz and Anne Mette Thorhauge explore the notion of risk in relation to intimate photo-sharing. Drawing on focus group interviews with German high school students, they demonstrate how risk plays a socially productive role in the establishment of intimate relationships, but is considered more acceptable in the case of friendly intimacy as compared to sexual or romantic intimacy.

In "Homosocial positionings and ambivalent participation: A qualitative analysis of young adults' non-consensual sharing and viewing of privately produced sexual images" Morten Birk Hansen Mandau unfolds sharing practices as an aspect of homosocial positionings. The boys and girls in Mandau's study use the sharing and viewing of (sexual) inti- 
mate photos as a way to position themselves, but they do this in quite different ways. The young boys use it as a resource for positioning themselves as more sexually experienced among their peers, while the girls use them to position themselves through devaluation of the depicted subject matter.

In "Travelling imagery: young people's sexualized digital practices" Penille Kærsmose Bøegh Rasmussen and Dorte Marie Søndergaard trace and map some of the different contexts of intimate photo-sharing. Drawing on a number of diverse empirical sources, the authors demonstrate the complexity of the technological and social environment that young people have to navigate, and the potentiality and unpredictability that this involves with regard to the photos in question.

In "Defying shame" Signe Uldbjerg Mortensen addresses the dynamics of digital exposure and shame between victims, aggressors, and the societies that they exist in. Signe Mortensen uses creative and therapeutic writing as a research method to present and elaborate the perspective of three victim-survivors of digital sexual assault, focusing on the notion of shame, the complexity of digital sexual assault, and the strategies that these young women use to defy their shame and to criticize a structure in which shame is attached to their sexuality rather than to the assaulting acts of the aggressors.

This issue also includes an Open Section article and two book reviews. In the article "To be a Bookeater: Literary debate in adolescent reading culture" Rasmus Grøn and AnneMette Albrechtslund present a case study analysis of a review forum for young readers of fantasy literature: Bookeater.dk. The authors argue that the reader's loyalty to this collective identity creates a culture of consensus rather than instigating critical discussions. This is explained by the dual purpose of the forum: providing a social setting for passionate young readers, while also having an educational purpose of inspiring the readers to express their literary valuations. However, in this case, this does not prompt a culture of actual debate.

In the first review, Kelechi Amakoh reviews "Gender and Media: Representing, Producing, Consuming" by Tonny Krijnen and Sofie Van Bauwel. This Routledge volume discusses the intersection between media and gender through the lenses of media representation, production, and consumption of media content. It also provides a critical angle to the several discourses on gender and media.

In the second review, Anne-Mette Bech Albrechtslund reviews Mie Femø Nielsen and Svend Skriver's "Metodekogebogen - 130 analysemetoder fra humaniora og samfundsvidenskab", which is a pragmatic introduction to a variety of methods for the humanities and social sciences that is written as an actual cook book, focussing on both the collection and the analysis of data. 
Editorial: Intimacy and visual communication in social media

\section{References}

Albury, K., \& Crawford, K. (2012). Sexting, consent and young people's ethics: Beyond Megan's Story. Continuum, 26(3), 463-473.

Harder, S.K., Jørgensen, K.E., Gårdshus, J.P., \& Demant, J. (2019). Digital sexual violence : Image-based sexual abuse among Danish youth. In M. Bruvik Heinskou, M.L. Skilbrei, \& K. Stefansen (Eds.), Rape in the Nordic Countries (pp. 205-223). London: Routledge.

Henson, B., Fisher, B. S., \& Reyns, B. W. (2019). There Is Virtually No Excuse: The Frequency and Predictors of College Students' Bystander Intervention Behaviors Directed at Online Victimization. Violence Against Women. 1-23. doi:10.1177/1077801219835050

Roberts, S., \& Ravn, S. (2019). Towards a Sociological Understanding of Sexting as a Social Practice: A Case Study of University Undergraduate Men. Sociology. doi:10.1177/0038038519864239

Walrave, M., Van Ouytsel, J., Ponnet, K., \& Temple, J. R. (2018). Sharing and Caring? The Role of Social Media and Privacy in Sexting Behaviour. In M. Walrave, J. Van Ouytsel, K. Ponnet, \& J. R. Temple (Eds.), Sexting: Motives and risk in online sexual self-presentation (pp. 1-17). Cham: Springer International Publishing.

Anne Mette Thorhauge Associate Professor

Department of communication University of Copehagen thorhaug@hum.ku.dk

Jakob Johan Demant Associate Professor Department of Sociology University of Copenhagen jd@soc.ku.dk

Stinne Gunder Strøm Krogager Associate Professor Department of Communication and Psychology Aalborg University stinne@hum.aau.dk 